\title{
Aortic surgery cost and outcome at teaching vs. non-teaching hospitals
}

\author{
Azam Jan ${ }^{1}$, Naseer Ahmed ${ }^{2}$, Mumtaz Anwar Shah ${ }^{1}$, Somiya Rehman', \\ Alessio Rungatscher², Giuseppe Faggian²
}

${ }^{1)}$ Department of Cardiac Surgery, Rehman Medical Institute, Peshawar, Pakistan.
${ }^{2)}$ Cardiac Surgery Division, University of Verona Medical School, Verona, Italy.

\begin{abstract}
Objective: The purpose of this was to investigate, if there is a difference in cost and outcomes of Aortic surgery in teaching hospitals as compared to non-teaching hospitals.

Methods: The Healthcare Cost and Utilization Project (HCUP), sponsored by The Agency for Healthcare Research and Quality's (AHRQ), includes the largest collection of longitudinal hospital care data in the United States of America. HCUP creates the National Inpatient Sample (NIS) to help conduct national and regional analyses of inpatient care. Using the NIS (2001-2012), we performed a retrospective cohort study that involved patients who underwent vascular. Bypass surgery involving major abdominal vessels. To identify these patients we used ICD (International Classification of Diseases) 9 procedure code 39.25. Using statistical analysis we compared the inpatient short term outcomes of these patients treated at teaching hospitals to non-teaching hospitals. Unweighted, it contains data from more than 7 million hospitalized patients stay each year. Weighted, it estimates more than 36 million hospitalizations nationally taken from more than 4,000 HCUP participating hospitals.
\end{abstract}

Results: A total of 15274 patients were analyzed from 2011-2012. There has been a marked decline in rate of Aortic bypass procedures per 100,000 discharges from 6.3 to 2.8 over the years 2001 to 2012.Also in these cases Routine discharges have decreased, the cost of stay and utilization of nursing home, rehabilitation and home health care has increased since 2001. There is no significant difference in inpatient mortality between teaching (3.06\%) and non-teaching hosp. (4.21\%). At teaching hospitals the cost of the admission for these aortic procedures was $6000 \$$ higher, the length of stay was longer. Overall the use of nursing home, rehabilitation and home health care is more by the academic hospitals. But there is no difference in utilization of these facilities when it is analyzed relative to total number of procedures, between teaching and non-teaching hospitals.

Conclusions: Teaching hospitals has similar mortality for aortic bypass procedures as compared to nonteaching hospitals but at a higher cost of re-admission and prolonged hospitalization.

Keywords: Vascular surgery, nursing home and rehabilitation, surgical mortality and morbidity.

Jan A. Ahmed N, Shah SM., Rehman S, Rungatscher A, Faggian G. Aortic surgery cost and outcome at teaching vs. nonteaching hospitals. EJCM 2016; 04 (3): 56-62. Doi: 10.15511/ejcm.16.00356.

Copyright (C) 2016 Heart and Health Foundation of Turkey (TÜSAV). Published by Medikal Akademi.

This article is licensed by Medikal Akademi and TÜSAV under the terms of Creative Commons Attribution License. 


\section{Introduction}

The university hospitals usually under pressure to face challenges for more complicated cases, patient care and research activities. ${ }^{[1-5]}$ The Committee on Quality of Health Care in America, of the "Institute of Medicine" concluded that it is not acceptable for patients to be harmed by the health care system that is supposed to offer healing and comfort-- a system that promises, 'First, do no harm' ${ }^{\text {[6] }}$ Similarly it is our duty to maintain high standards of medical training for the doctors and other medical professionals of the future, at hospitals, without compromising any patient safety issues. Tremendous effort has been put in to implement and assess these two fundamental goals of academic medical institutions. There are different studies looking at the impact of trainees involved in surgical cases, showing difference in operating time and transfusion requirements etc. ${ }^{[7]}$ We wanted to see how adding teaching to health care institutions would actually impact treatment of surgery patients. To investigate that we decided to look at the multiyear data provided by The Agency for Healthcare Research and Quality's (AHRQ). ${ }^{[8]}$

\section{Materials and Methods}

AHRQ's mission is to produce evidence to make health care safer, higher quality, more accessible, equitable, and affordable. The Healthcare Cost and Utilization Project (HCUP) is a family of databases and related software tools and products developed through a Federal-State-Industry partnership and sponsored by AHRQ. HCUP includes the largest collection of longitudinal hospital care data in the United States. The data in the HCUP databases primarily include data from non-federal community hospitals. HCUP creates the National Inpatient Sample (NIS) to make it possible for researchers to conduct national and regional analyses of hospital use and the hospital charges and costs associated with inpatient care. The NIS is derived from the State Inpatient Databases (SID) and approximates a 20\% sample of discharges from all HCUP community hospitals in the U.S. The NIS is the largest publicly available all-payer inpatient health care database in the United States, yielding national estimates of hospital inpatient stays. Unweighted, it contains data from more than 7 million hos- pital stays each year. Weighted, it estimates more than 36 million hospitalizations nationally taken from more than 4,000 HCUP participating hospitals.

We wanted to primarily assess the impact of the academic status of the institutions on patient outcome of surgery patients. Hence we picked up a group of surgeries performed at hospitals, which would have required multidisciplinary perioperative and intraoperative management. With this in mind, using the National Inpatient Sample database, we performed a retrospective cohort study that involved patients who underwent vascular Bypass surgery involving major abdominal vessels. The Institutional Review Board approval was waived. To identify these patients we used ICD 9 CM procedure code $39.25 .{ }^{[9]}$ This code includes the following procedures aorto-femoral, aorto-iliac, aorto-iliac to popliteal, aorto-popliteal and ilio-femoral bypass. Then using national estimates, we identified associations of patient demographics, and hospital characteristics with inpatient postoperative outcomes. We queried our desired ICD 9 code using HCUP net, which is a free, online query system based on NIS data.

The definition of all the patients, hospital demographics and outcome measures are available on HCUP net. We first analyzed the national trends of this ICD code from year 2001 to 2012. Then we restricted the discharges to Operating room procedures only, which are defined as "valid O.R. procedures" based on Diagnosis Related Groups coding principles. Then we did a detailed analysis of 2012 data, so that we can have outcomes representing the most recent advances in medical care provided in the latest academic environment. Using this data we did stratification based on the teaching status of the institution.

According to NIS a hospital is considered a teaching hospital if it meets any one of the following three criteria: Residency training approval by the Accreditation Council for Graduate Medical Education (ACGME),Membership in the Council of Teaching Hospitals (COTH) or A ratio of full-time equivalent interns and residents to beds of 25 or higher. We analyzed 2012 variables "Urban nonteaching" and "Urban teaching" and their effect on mortality and discharge status. In addition we also investigated 
effect of hospital volume and geographical location on inpatient outcomes.

We used Excel and HCUP Z score calculator for our statistical analysis. We considered a $\mathrm{p}$ value of less than 0.05 for significance. For continuous data we analyzed the actual numbers and for dichotomous data we used percentage comparisons to get a more meaningful result.

\section{Results}

NIS database in the United States, unweighted, contains data from more than 7 million hospital stays each year. Weighted, it estimates more than 36 million hospitalizations nationally taken from more than 4,000 hospitals. A total of 152,474 patients were discharged with a primary ICD procedure code of major abdominal vascular procedures (39.25) from 2001 to 2012. There was a decline (significant $\mathrm{p}$ value $<0.05$ ) in total discharges (from 18065 to 8755 ) and rate of discharge per 100,000 persons (6.3 to 2.8)from 2001 to 2012. (Figure 1). The Length of stay remained constant around 8 days during this time period.
The total charges of these procedures (ICD code 39.25 ) has increased significantly to more than $100,000 \$$ in 2012 which was more than double of what it was in 2001. Also there is a significant decrease of $10 \%$ in routine discharges but no difference in discharge to another short term hospital since 2001. There is a $3 \%$ increase in use of nursing home, rehabilitation institutions and $8 \%$ increase in home health care since 2001. There is a statistically significant decrease in number of deaths from 2001 to 2012 i.e. 794 to 305 respectively but the percentage decrease in mortality from $4.39 \%$ to $3.48 \%$ ( $\mathrm{p}$ value 0.09 ) has a decreasing trend but (at $\mathrm{p}$ value of 0.05$)$ is not significant.

Total of 8755 patients were discharged with this ICD code in 2012.In $201260 \%$ patients were males, Medicare was the payer of $50 \%$ patients and $30 \%$ patients had insurance. $78 \%$ admissions were at private-not for profit institutions, $60 \%$ were at teaching hospitals and $47 \%$ patients were from south region.

In total 5230(60\%)were from urban teaching hospi-

Figure 1. 2001-2012 National statistics (ICD code) 39.25 for Aortic Bypass. Weighted national estimates from HCUP National Inpatient Sample (NIS).

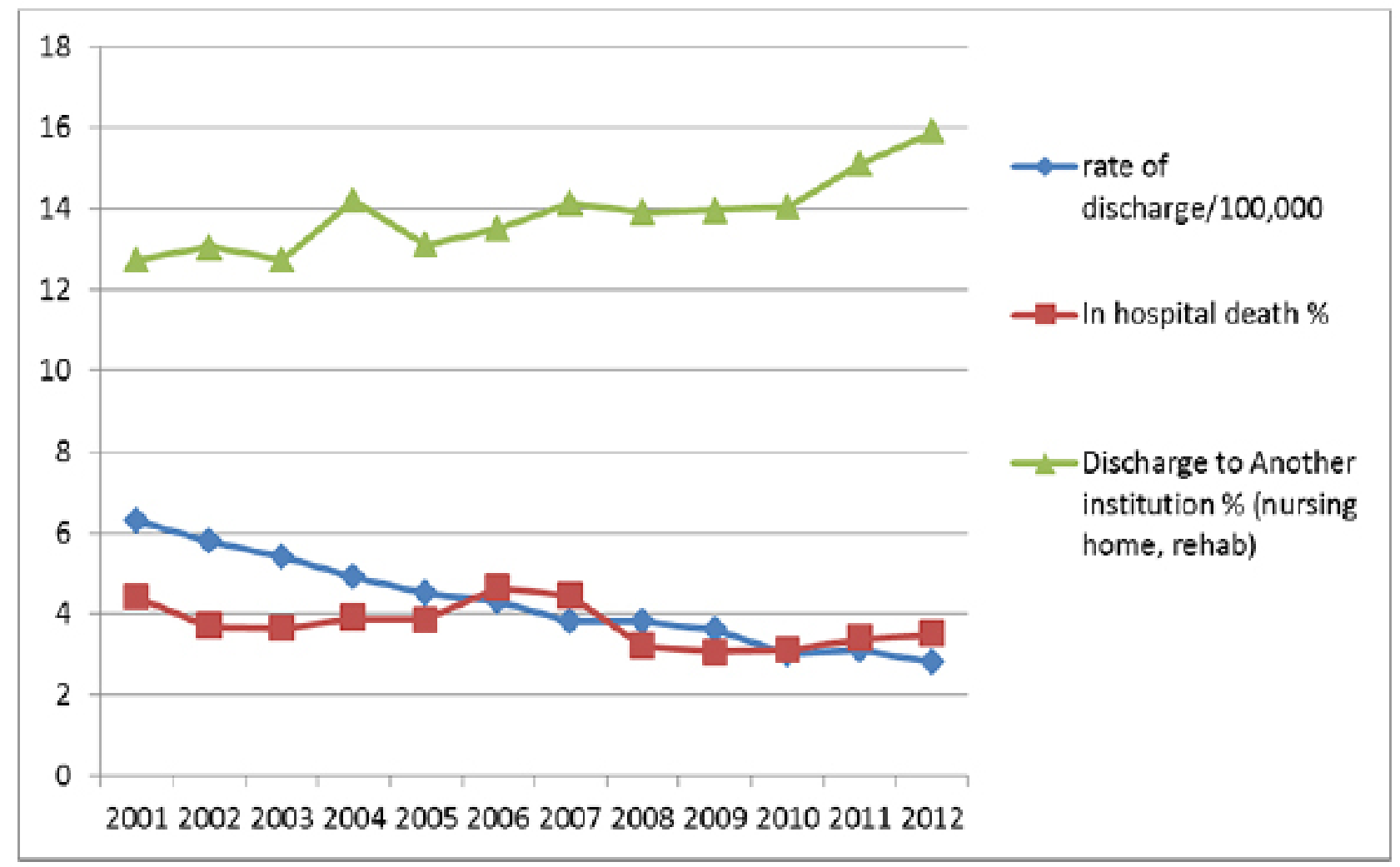


tals and 2970(34\%)were from non-teaching hospitals. $6 \%$ patients were from rural hospitals, so their data were not included in further analysis of 2012 data.

There were significantly more discharges from urban teaching hospitals (Table 1). Discharges from teaching hospitals had statistically significant differences as compared to nonteaching hospitals, including a longer length of stay, more cost of treatment, less routine discharges, more discharges to nursing home and rehab and more utilization of home health care when total numbers were analyzed. When we did comparison based on percentage differences there was no statistical difference between routine discharges, discharges to nursing home and rehab and utilization of home health care. Although there was a lower Inpatient mortality, by $1 \%$, at teaching hospitals, this difference was not statistically significant.

We analyzed risk factors for higher mortality (Table 2). Risk factor for higher mortality was age of 65 to 84 and factors that did not have statistically different im- pact on mortality included sex of the patient, teaching status of the hospital, geographical location, and median income for the zip code, ownership type and size of the hospital.

\section{Discussion}

We had a large number of patient population and very reliable data source to analyze. But these databases are derived from billing data and some useful data, such as pharmacy and laboratory information, are not included. Also, as with any administrative healthcare database, there may be issues with coding accuracy. But still with a large number of patients, very useful assumptions can be made. There are different aortic procedures included in our research design, which in turn vary in complexity and periprocedural risk of death and complications. The decrease in overall rate of these procedures over the years probably corresponds to the increase in endovascular procedures. That probably also has an impact on increase in the complexity of these procedures. As more complicated procedures are being performed as

\section{Table 1. Academic status of the hospital and Inpatient Postop. outcomes of vascular surgery patients( ICD 939.25 Aorta-Iliac-Femoral Bypass)}

\begin{tabular}{|l|c|c|c|}
\hline 2012 year & $\begin{array}{c}\text { Non-teaching } \\
\text { Hosp. }\end{array}$ & $\begin{array}{c}\text { Urban Teaching } \\
\text { Hosp. }\end{array}$ & P value (two tail) \\
\hline Total number of discharges & 2970 & 5230 & 0.00 (significant) \\
\hline LOS (length of stay), days (mean) & 7.7 & 9.2 & 0.00 (significant) \\
\hline Costs, \$ (mean) & 25237 & 31579 & 0.00 (significant) \\
\hline In-hospital deaths & $125(4 \%)$ & $160(3 \%)$ & 0.23 (non sign \% diff.) \\
\hline Routine Discharge & $1855(62 \%)$ & $3060(59 \%)$ & 0.15 (nonsign \% diff) \\
\hline $\begin{array}{l}\text { Discharge to Another institution } \\
\text { (nursing home, rehab) }\end{array}$ & $435(15 \%)$ & $895(17 \%)$ & 0.20 (nonsign \% diff) \\
\hline Home health care & $510(17 \%)$ & $1050(20 \%)$ & 0.20 (nonsign \% diff) \\
\hline
\end{tabular}

Weighted national estimates from HCUP National Inpatient Sample (NIS), 2012. Significant at $p<.05$ 
Table 2. 2012 National statistics (ICD code) 39.25 Aorta-lliac-Femor Bypass Mortality

\begin{tabular}{|c|c|c|c|c|}
\hline \multirow{2}{*}{ All discharges } & & $\begin{array}{l}\text { Total number } \\
\text { of discharges }\end{array}$ & $\begin{array}{l}\text { In-hospital } \\
\text { deaths }\end{array}$ & $\begin{array}{l}\mathrm{Z} \text { test between } \% \text { of } \\
\text { in hospital deaths }\end{array}$ \\
\hline & & $\begin{array}{c}8,755 \\
(100.00 \%)\end{array}$ & $\begin{array}{c}305 \\
(3.48 \%)\end{array}$ & $\begin{array}{l}\text { P value } \\
\text { (two tail) }\end{array}$ \\
\hline \multirow{6}{*}{ Age group } & $<1$ & * & * & \multirow{6}{*}{$\begin{array}{c}0.00 \\
\text { (significant) Between } \\
\text { 45-64 and 65-84 }\end{array}$} \\
\hline & $1-17$ & * & * & \\
\hline & $18-44$ & $265(3.03 \%)$ & * & \\
\hline & $45-64$ & $4,935(56.37 \%)$ & $85(1.72 \%)$ & \\
\hline & $65-84$ & $3,425(39.12 \%)$ & $200(5.84 \%)$ & \\
\hline & $85+$ & $120(1.37 \%)$ & * & \\
\hline \multirow{2}{*}{ Sex } & Male & $5,230(59.74 \%)$ & $185(3.54 \%)$ & \multirow{2}{*}{$\begin{array}{c}0.09 \\
\text { (Non sig) Male and female }\end{array}$} \\
\hline & Female & $3,525(40.26 \%)$ & $120(3.40 \%)$ & \\
\hline \multirow{6}{*}{ Payer } & Medicare & $4,370(49.91 \%)$ & $220(5.03 \%)$ & \\
\hline & Medicaid & $1,035(11.82 \%)$ & * & \\
\hline & Private insurance & $2,540(29.01 \%)$ & * & \\
\hline & Uninsured & $480(5.48 \%)$ & * & \\
\hline & Other & $275(3.14 \%)$ & * & \\
\hline & Missing & * & * & \\
\hline \multirow{2}{*}{$\begin{array}{l}\text { Median income } \\
\text { for Zip code }\end{array}$} & Low & $2,905(33.18 \%)$ & $95(3.27 \%)$ & \multirow{2}{*}{$\begin{array}{l}0.64 \text { (non significant) } \\
\text { Low vs. Not Low }\end{array}$} \\
\hline & Not low & $5,695(65.05 \%)$ & $210(3.69 \%)$ & \\
\hline \multirow{3}{*}{ Owner } & Government & $840(9.59 \%)$ & * & \multirow{3}{*}{$\begin{array}{c}0.09 \text { (non significant) } \\
\text { Private Not for profit vs. } \\
\text { private for profit }\end{array}$} \\
\hline & Private, not-for-profit & 6,795 (77.61\%) & $210(3.09 \%)$ & \\
\hline & Private, for-profit & $1,120(12.79 \%)$ & $65(5.80 \%)$ & \\
\hline \multirow{3}{*}{$\begin{array}{l}\text { Location I } \\
\text { teaching } \\
\text { status }\end{array}$} & Rural & $555(6.34 \%)$ & * & \multirow{3}{*}{$\begin{array}{c}0.23 \\
\text { (non significant) } \\
\text { Nonteaching vs. teaching }\end{array}$} \\
\hline & Urban nonteaching & $2,970(33.92 \%)$ & $125(4.21 \%)$ & \\
\hline & Urban teaching & $5,230(59.74 \%)$ & $160(3.06 \%)$ & \\
\hline \multirow{3}{*}{ Bedsize } & Small & $860(9.82 \%)$ & * & \multirow{3}{*}{$\begin{array}{c}0.21 \\
\text { (non significant) } \\
\text { Medium vs. Large }\end{array}$} \\
\hline & Medium & $1,820(20.79 \%)$ & $80(4.40 \%)$ & \\
\hline & Large & $6,075(69.39 \%)$ & $180(2.96 \%)$ & \\
\hline \multirow{4}{*}{ Region } & Northeast & $1,275(14.56 \%)$ & * & \multirow{4}{*}{$\begin{array}{c}0.377 \\
\text { (non significant) } \\
\text { Midwest vs. south }\end{array}$} \\
\hline & Midwest & $2,445(27.93 \%)$ & $100(4.09 \%)$ & \\
\hline & South & $4,135(47.23 \%)$ & $130(3.14 \%)$ & \\
\hline & West & $900(10.28 \%)$ & & \\
\hline
\end{tabular}

Weighted national estimates from HCUP National Inpatient Sample (NIS), 2012. Statistics based on estimates with a relative standard error (standard error / weighted estimate) greater than 0.30 or with standard error $=0$ are not reliable. These statistics are suppressed and are designated with an asterisk $\left({ }^{*}\right)$. Significant at $p<.05$ 
open aortic bypasses, we expect more utilization of rehabilitation and nursing homes. That could be one of the reasons for that change over the decade studied.

Teaching hospitals have an increased cost and longer stay for surgical admissions. As any one vascular procedure can be performed for different reasons that reflect different levels of disease severity, which can influence unadjusted rates of events. For instance, the same aorto-femoral bypass can be performed for gangrene of the foot to prevent amputation, or alternatively for intermittent claudication or an aneurysmal condition. Comparison of outcomes among different vascular surgery practices must therefore account for potential differences in the range of procedures being performed. If teaching hospitals are undertaking more complicated procedures then some of the differences can be explained. From our study, we assumed that there is no significant different between teaching and non teaching hospitals mortality rate. And if that is the case then having a similar mortality hints towards providing better care. It could be that the trainees order more diagnostic tests and assess discharge disposition differently than consultant physicians?

\section{Limitations}

We used national database, where we have limitations in some data and some parameters to assess investigations level. Having 30 day mortality data and more detail of patient demographics will help us throw more light on quality of care.

\section{Conclusion}

Teaching hospitals has similar mortality for aortic surgery procedures as compared to non-teaching hospitals but at a higher cost of admissions and prolonged hospitalization.

Acknowledgements: The authors acknowledge all of the HCUP Data Partners that contribute to HCUP. List of these State organizations can be accessed at (www.hcupus.ahrq.gov/hcupdatapartners.jsp). 


\section{References}

1. Iglehart JK. Rapid changes for academic medical centers. N Engl J Med 1994; 331: 1391-1395.

2. Epstein AM. US teaching hospitals in the evolving health care system. JAMA 1995; 273: 1203-1207.

3. Iglehart JK. Rapid changes for academic medical centers, II. N Engl J Med 1994; 332: 407-411.

4. Kassirer JP. Academic medical centers under siege. N Engl J Med 1994; 331: 1370-1371.

5. Whitcomb ME, Cleverly WO. Financial performance of academic medical center hospitals. Acad Med 1993; 68: 729-731

6. Linda T. Kohn, Janet M. Corrigan, and Molla S. Donaldson. November 1999 Shaping the Future for Health TO ERR IS HUMAN: BUILDING
A SAFER HEALTH SYSTEM. Committee on Quality of Health Care in America, INSTITUTE OF MEDICINE.NATIONAL ACADEMY PRESS. Washington, D.C.

7. Azam Jan, MD, Dale R. Riggs, BA, Keri L. Orlando, RN†, Fawad J. Khan, MD.Surgical Outcomes Based on Resident Involvement: What Is the Impact on Vascular Surgery Patients? Journal of Surgical Edu. Volume 69, Issue 5, September-October 2012, Pages 638-642

8. The Agency for Healthcare Research and Quality's (AHRQ), The Healthcare Cost and Utilization Project (HCUP), State Inpatient Databases (SID) and National Inpatient Sample (NIS) . http://www.ahrq.gov

9. The Centers for Medicare \& Medicaid Services ICD 9 CM : International Classification of Diseases, Clinical Modification .

Received: 17/07/2016

Accepted: 02/09/2016

Published: 15/09/2016

Disclosure and conflicts of interest:

Article have been presented at 12th Update congress of Cardiology and Cardiac Surgery, (10th March-13th March 2016) Antalya, Turkey.

\section{Corresponding author:}

Naseer Ahmed

Mail: dr.naseer99@gmail.com 